\title{
Palliative analgesia with topical sevoflurane in cancer-related skin ulcers: a case report
}

\author{
F Dámaso Fernández-Ginés, ${ }^{1}$ Manuel Cortiñas-Sáenz, ${ }^{2}$ \\ Ana Navajas-Gómez de Aranda, ${ }^{3}$ Maria del Carmen Navas-Martinez, ${ }^{4}$ \\ José Antonio Morales-Molina, ${ }^{5}$ Francisco Sierra-García, ${ }^{1}$ Héctor Mateo-Carrasco ${ }^{6}$
}

\begin{abstract}
- Additional material is published online only. To view please visit the journal online (http://dx.doi.org/ 10.1136/ejhpharm-2017001421)
\end{abstract}

${ }^{1}$ Pharmacy Department, Torrecárdenas Hospital, Almería, Spain

${ }^{2}$ Torrecárdenas Hospital

Almería, Spain

${ }^{3}$ Anaesthesiology and Critical

Care Medicine Department,

Torrecárdenas Hospital,

Almería, Spain

${ }^{4}$ Urology Department,

Torrecárdenas Hospital,

Almería, Spain

${ }^{5}$ Pharmacy Department, Hospital of Poniente, Almería, Spain

${ }^{6}$ Royal Marsden NHS

Foundation Trust, London, UK

Correspondence to

F Dámaso Fernández-Ginés,

Pharmacy Department,

Torrecárdenas Hospital, Almería

04009, Spain; fdamaso.

fernandez@gmail.com

Received 11 October 2017

Accepted 19 December 2017

Published Online First

11 January 2018

Check for updates

To cite: Fernández-Ginés FD, Cortiñas-Sáenz M, NavajasGómez de Aranda A, et al. Eur J Hosp Pharm

2019:26:229-232

\section{SUMMARY}

A Caucasian 39-year-old male patient with a poorlydifferentiated infiltrating epidermoid penile carcinoma with urethral invasion was diagnosed. The patient received concomitant adjuvant chemotherapy with radiotherapy in the palliative setting, which produced painful ulceration of tumour lesions at loco-regional level (Numerical Rate Scale, NRS=9). The patient consented for treatment with direct topical sevoflurane instillations, at initial doses of $1 \mathrm{~mL} / \mathrm{cm}^{2}$ of ulcerated area, as per unit protocol. The local use of undiluted sevoflurane achieved a marked reduction of the pain score in both nociceptive and irruptive pains (average NRS $=3$ immediately postapplication). This improvement was corroborated by a decline in total morphine needs, any adverse events associated with major opiates. PGI-I and CGI-I scales were used before and after treatment with topical sevoflurane to assess patient and clinician perceptions of improvement in the quality of life. The pharmacy of our hospital had the responsibility to elaborate pre-loaded syringes with sevoflurane so that the patient was instilled simply and comfortably.

\section{BACKGROUND}

The pharmacy of our hospital had the responsibility of elaborating the syringes preloaded with sevoflurane under sterile working conditions in a vertical laminar flow hood, taking into account that the syringe was opaque, polypropylene material with a stopper that would avoid the exit of the volatile liquid, the aim of which was that the both the patient themselves at home and the nursing staff could instil sevoflurane on the ulcer easily and comfortably.

This paper describes the emerging off-label use of topical sevoflurane in painful skin ulcers, as well as highlighting the role of the pharmacist in an area with traditional low clinical input from the pharmacy team.

\section{CASE PRESENTATION}

This paper concerns a Caucasian 39-year-old male patient with a diagnosis of poorly-differentiated infiltrating epidermoid penile carcinoma with urethral invasion, first diagnosed in 2014. The past medical history of the patient was significant for smoking (15 pack-years), high blood pressure and previous left myocardial infarction (2013). The patient had a partial penectomy in August 2014. In 2015, new palpable right inguinal adenopathies were evidenced (upgrading the tumour to
pT3N2M1), for which the patient had an iliac and inguinal lymphadenectomy, plus complete scrotal resection.

The patient received concomitant adjuvant chemotherapy as palliative treatment with weekly cisplatin $30 \mathrm{mg} / \mathrm{m}^{2}$ during 6 weeks in combination with $18 \mathrm{MV}$ photon radiotherapy (reaching a dose of $56 \mathrm{~Gy}$ ), which produced ulceration of tumour lesions at loco-regional level.

Following this, 6 months after the first dose of the chemotherapy, the patient received one cycle of weekly paclitaxel $80 \mathrm{mg} / \mathrm{m}^{2}$ (days 1,8 and 15 ). This was discontinued due to fever and general decay. Finally, the patient was referred to the Palliative Care Unit in December 2015 for the palliative management of the disease.

Shortly after, the patient developed increasingly painful inguinal ulcers, reaching $13 \mathrm{~cm}^{2}$ in size and a score of 9 in the Numerical Ratings Scale (NRS). Pain relief therapy consisted of high-dose opioids (equivalent to $800 \mathrm{mg} /$ day of morphine base), plus other adjuvant pain-relief measures and standard wound care. These therapies proved ineffective for pain control, further resulting in nausea and constipation due to high-dose opioids.

Patient Global Impression of Improvement (PGI-I) and Clinical Global Impression of Improvement (CGI-I) scales ${ }^{1}$ were used before and after treatment with topical sevoflurane to assess patient and clinician perceptions of improvement in the quality of life, respectively.

\section{INVESTIGATIONS}

The prevalence of tumour-related skin ulcers is estimated between $0.6 \%$ and $9 \%$ for all tumour types. ${ }^{2}$ Their pharmacological management is complex and may require the use of strong opioids and in some cases even sedative agents to alleviate the associated pain. ${ }^{34}$ Nevertheless, the evidence supporting the use of topical analgesia is unclear. ${ }^{4}$

Sevoflurane (CH2F-OCH[CF3]2) is a highly-fluorinated methyl-isopropyl ether-derivative widely used in the induction and maintenance of general anaesthesia in adult and paediatric patients. ${ }^{5}$ Sevoflurane (Sevorane, AbbVie, Campoverde di Aprilia, Italy) induces muscle relaxation and reduces pain sensitivity by decreasing the extent of gap junction mediated cell-cell coupling and altering the activity of the channels that underlie the action potential. ${ }^{4}$ In addition, sevoflurane exhibits in vitro broad-spectrum bactericidal action. ${ }^{6}$

In recent years, emerging evidence shows beneficial effects derived from the use of topical 


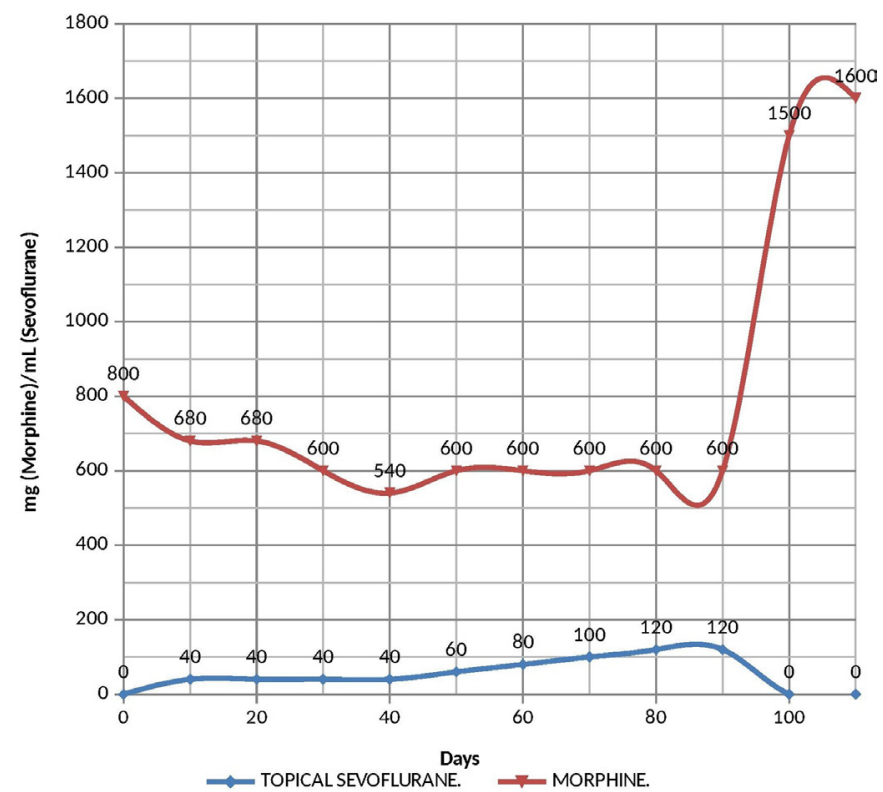

Figure 1 Morphine sulphate $(\mathrm{mg})$ and sevoflurane $(\mathrm{mL})$ requirements over time.

sevoflurane in the management of vascular ulcers. The novel use of topical sevoflurane as a local anaesthetic has generated interest among clinicians, due to the seemingly intense and durable pain relief induced after topical application..$^{711}$ In this respect, a pilot study on the role of topical instillations of sevoflurane in the management of refractory chronic venous ischaemic ulcers recently published by this group showed a marked reduction in pain scores, as well as promoting wound healing. ${ }^{10}$

The safe use of topical sevoflurane at high doses as an adjuvant treatment to standard analgesia and other pharmacologic and non-pharmacologic measures in the management of a patient with complicated primary penile skin neoplasia is reported and discussed herein.

\section{TREATMENT}

In view of the fact that the pain associated with the ulcers represented a therapeutic challenge, the patient was offered the possibility of receiving treatment with topical sevoflurane in an off-label indication.

The patient signed the informed consent for treatment with direct topical sevoflurane instillations as per the Pain Unit local protocol (see online supplementary additional material). $1 \mathrm{~mL} /$ $\mathrm{cm}^{2}$ of ulcerated area.

The self-reported baseline resting pain score was 9, despite high opioid doses. Five minutes post-application (requiring $40 \mathrm{~mL}$ of sevoflurane), the pain score was reduced to NRS $=3$. The analgesic effect was maintained for 24 hours for the first weeks of use. However, due to the quickly-progressing course of the disease, these doses had to be increased to $40 \mathrm{~mL}$ every 8 hours $(120 \mathrm{~mL}$ daily) to achieve good pain control. Throughout treatment, the patient did not present any local or systemic adverse effects related to the application of topical sevoflurane.

PGI-I and CGI-I scales were used on the patient before starting with topical sevoflurane to assess quality of life pre-and-post sevoflurane, obtaining a result of 'a little better' in both cases.

\section{OUTCOME AND FOLLOW-UP}

In combination with wound hygiene and best supportive care, sevoflurane instillations achieved a marked and durable pain
Table 1. Evolution in time of renal, hepatic andhaematologic function, and electrolyte balance during sevoflurane treatment

\begin{tabular}{|c|c|c|c|c|c|c|}
\hline \multirow[b]{2}{*}{ Reference values } & & \multicolumn{5}{|c|}{ Time (days) } \\
\hline & & $\begin{array}{l}\text { Basal } \\
\text { value }\end{array}$ & 15 & 30 & 60 & 90 \\
\hline Urea (mg/dL) & $10-50$ & 39.1 & 62.4 & 88.2 & 71.1 & 52.6 \\
\hline Creatinine(mg/dL) & $0.2-1.3$ & 0.91 & 0.46 & 0.59 & 0.61 & 0.45 \\
\hline Bilirrubin (mg/dL) & $0.1-1.3$ & 1.18 & 0.68 & 0.87 & 1.62 & 0.96 \\
\hline AST (U/L)* & $4-38$ & 31.2 & 24.2 & 19.8 & 15.4 & 14.2 \\
\hline GPT $(\mathrm{U} / \mathrm{L}) \dagger$ & $4-40$ & 49.9 & 40.2 & 41.1 & 30.1 & 27.4 \\
\hline GGT (U/L)‡ & $8-61$ & 59.3 & 829 & 897 & 1439 & 1578 \\
\hline Sodium (mEq/L) & $136-145$ & 140 & 130 & 131 & 133 & 130 \\
\hline Potassium (mEq/L) & $3.3-5.1$ & 4.93 & 4.74 & 4.74 & 4.49 & 5.81 \\
\hline Calcium (mg/L) & $8.4-10.2$ & 11.2 & 11.7 & 11.9 & 12.6 & 12.5 \\
\hline Haemoglobin (g/dL) & $13-16.5$ & 12.2 & 10.6 & 10.2 & 8.81 & 8.9 \\
\hline Leukocytes (cel/ $/ \mathrm{mm}^{3}$ ) & $4.8-10.8$ & 7.88 & 47.9 & 20.5 & 36.5 & 27.7 \\
\hline Platelets (cel/mm³) & $130-450$ & 184 & 637 & 476 & 382 & 268 \\
\hline INR§ & $0.84-1.16$ & 1.05 & 1.12 & 0.99 & 0.97 & 1.09 \\
\hline TpTA (seconds)ף & $0.8-1.2$ & 1.02 & 1.04 & 0.96 & 1.03 & 1.08 \\
\hline $\operatorname{CRP}(\mathrm{mg} / \mathrm{dL})^{* *}$ & $0.0-0.5$ & 0.42 & 45.6 & 22.8 & 25.3 & 16.5 \\
\hline
\end{tabular}

${ }^{*}$ Aspartate aminotransferase.

†Glutamic-pyruvic transaminase.

‡Gamma-glutamyl transpeptidase.

§International Normalised Ratio.

१Activated Partial Thromboplastin Time

${ }^{* *} \mathrm{C}$-reactive protein.

reduction of both baseline nociceptive pain (average of a NRS score of 3 immediately post-application), and irruptive pain (associated with wound cleansing) (average NRS of 3 immediately post-application), as well as minimising the need for immediate-release morphine sulphate administrations (see figure 1).

Nonetheless, the sevoflurane daily requirements increased progressively, parallel to the appearance of new ulcerative inguinal lesions, achieving a total of $120 \mathrm{~mL} /$ day in three divided doses. In 2016, 3 months after the initiation of treatment with sevoflurane, a number of systemic complications associated with the natural course of the disease and the patient baseline pathologies (repeated urinary tract infections, hypochromic anaemia, electrolyte disturbances, severe protein-energy malnutrition and respiratory insufficiency) lead to multi-organ failure and death. As we can see in figure 1, topical sevoflurane is interrupted at 100 days due to clinical worsening of the patient and subsequent sedation.

In this report, the patient achieved a remarkable, immediate and durable (24hours of analgesic effect) reduction in pain scores, which was accompanied by an improvement in quality of life because pain perception ratings of 'much better' relative to specified points on the PGI-I and CGI-I scales. The improvement of pain was corroborated by the decline in total morphine needs (see figure 1), particularly in the first 40 days of treatment, although eventually the patient required progressive increases in daily requirements due mostly to deterioration of his condition and increment of the ulcerated area.

An episode of moderate hypercalcaemia (see table 1) was observed. No systemic effects or other sevoflurane-mediated toxicities were observed through the entire period of study, as evidenced by the periodical clinical assessments and laboratory results. This is persuasive of a negligible absorption after topical administration, despite the increased tissue permeability, being the sole adverse event associated with topical sevoflurane administrations, the appearance of a reddened itchy zone surrounding the application. 


\section{DISCUSSION}

The evidence supporting the use of topical anaesthesia in wounds associated with pain is not conclusive and somewhat controversial. ${ }^{4}$ A 2012 Cochrane review evaluating eight randomised clinical trials totalling 813 patients showed an improvement in debridement pain in patients receiving an eutectic mixture of local anaesthetic (lidocaine-prilocaine 5\%), or slow release foam ibuprofen dressings compared with placebo. ${ }^{12}$ Additionally, some studies reported positive outcomes in pain scores and wound healing of topical nitroglycerin, honey or capsaicin preparations. $^{13-15}$

This case showed a beneficial effect of topical sevoflurane instillations in achieving reductions of pain scores in both nociceptive and irruptive pain in a patient with severe skin ulcers associated with metastatic penile cancer. This is in line with a previous report by this group in a patient with metastatic rectal cancer-related cutaneous ulcers, and although conducted in a different setting, as well as with previous reports of poorly-controlled varicose and ischaemic vascular ulcers published by other authors. $^{8-1113}$

The mechanism through which sevoflurane achieves its analgesic effect remains unclear. A work by Fassoulaki et al suggested that a high sevoflurane intracellular pool promotes the activation of potassium channels and inactivation of sodium channels, which would be ultimately responsible for its peripheral analgesic actions, although the role of calcium channels is still to be elucidated. ${ }^{16}$ Cantrell et al published a case of abuse by sevoflurane with an analysis of severe hypocalcaemia and hyperkalaemia, probably due to a release of inorganic fluoride from the metabolism of this in the plasma. ${ }^{17}$ It is also noteworthy that calcium levels were elevated in this patient: the hypercalcaemia could be explained by the overproduction of parathormone-like substances secreted by the epidermoid carcinoma. ${ }^{18}$ Additionally, sevoflurane has been related to high calcium levels. ${ }^{19}$

In addition to its analgesic effect, sevoflurane has been attributed to antimicrobial and pro-epithelising effects. Its antibacterial actions derive from its cell membranes' solvent properties, which seem to be more prominent against gram-negatives. In this case, it is unclear whether the non-occurrence of wound infections or other complications associated with bacterial overgrowth were in relation to the local use of the halogenated agent, since the patient received several courses of broad-spectrum antibiotics due to repeated urinary tract and respiratory infections during the treatment period. ${ }^{20-23}$ Likewise, it was difficult to determine if any other action, particularly wound healing, occurred as a result of the use of the anaesthetic, mostly due to the progression of the underlying process.

Some evidence though points towards the fact that the promotion of wound healing could be actually derived from a combination of other actions such as better pain control (allowing better cleaning and debridement, thus in turn resulting in better oxygenation of the tissues) and the suppression of bacterial overgrowth. ${ }^{24}$

In conclusion, this report highlights the use of topical instillations of sevoflurane directly over the skin lesion in the management of cancer-associated cutaneous ulcers refractory to high-dose opioids plus other hygienic measures. Sevoflurane achieved immediate, intense and durable pain relief when used in combination with standard hygienic measures and analgesia, or where these alone failed to achieve its purpose. As well as having some other advantages (good penetration due to its liquid form, ease of use, absence of side effects, and potential antibacterial and healing-promoting actions) suggest that topical sevoflurane might play a role in the management of refractory ulcers in palliative care for cancer patients. However, further research in a larger population is required to confirm these properties, as well as to analyse its long-term risk-benefits.

\section{Learning points}

- This novel treatment offers an effective treatment in the pain management of ulcers in palliative care for cancer patients

- The daily morphine requirements decreased during sevoflurane use, thus resulting in fewer adverse events associated with high doses of opioids

- The patient tolerated long-term use of sevoflurane at the highest dose ever reported in an oncological ulcer, without adverse events.

Correction notice This paper has been amended since it was published Online First. The corresponding author has asked us to insert an acknowledgments section.

Acknowledgements The personnel of the pharmacy and Pain Unit departments of Torrecárdenas Hospital are acknowledged for their collaboration in the study. The study results were included in work submitted by Mr F Dámaso Fernández-Ginés as part of requirements of the doctorate program in pharmacy at the University of Granada, Granada, Spain.

Contributors All authors contributed equally.

Competing interests None declared.

Patient consent Obtained

Ethics approval Ethical committee of the Hospital Complex Torrecardenas.

Provenance and peer review Not commissioned; externally peer reviewed.

(C) European Association of Hospital Pharmacists (unless otherwise stated in the text of the article) 2019. All rights reserved. No commercial use is permitted unless otherwise expressly granted.

\section{REFERENCES}

1 Hurst $\mathrm{H}$, Bolton J. Assessing the clinical significance of change scores recorded on subjective outcome measures. J Manipulative Physiol Ther 2004;27:26-35.

2 da Costa Santos CM, de Mattos Pimenta CA, Nobre MR. A systematic review of topical treatments to control the odor of malignant fungating wounds. J Pain Symptom Manage 2010;39:1065-76.

3 Woo KY, Sibbald RG. Local wound care for malignant and palliative wounds. Adv Skin Wound Care 2010;23:417-28.

4 Argoff CE. Topical analgesics in the management of acute and chronic pain. Mayo Clin Proc 2013;88:195-205.

5 Preckel B, Bolten J. Pharmacology of modern volatile anaesthetics. Best Pract Res Clin Anaesthesiol 2005;19:331-48.

6 Martínez-Serrano M, Gerónimo-Pardo M, Martínez-Monsalve A, et al. Antibacterial effect of sevoflurane and isoflurane. Rev Esp Quimioter 2017:30:84-9.

7 Gerónimo-Pardo M, Martínez-Monsalve A, Martínez-Serrano M. Analgesic effect of topical sevoflurane on venous ulcer intractable pain. Phlebologie 2011:95-7.

8 Martinez-Monsalve A, Gerónimo-Pardo M. Sevoflurano como anestésico local en herida isquémica de paciente cardiópata con insuficiencia respiratoria secundaria a morfina. Heridas y Cicatrización 2011;6:46-9.

9 Imbernón A, Blázquez C, Puebla A, et al. Chronic venous ulcer treatment with topical sevoflurane. Int Wound J 2016;13:1060-2.

10 Dámaso Fernández-Ginés F, Cortiñas-Sáenz M, Mateo-Carrasco H, et al. Efficacy and safety of topical sevoflurane in the treatment of chronic skin ulcers. Am J Health Syst Pharm 2017;74:e176-e182.

11 Fernández-Ginés FD, Cortiñas Sáenz M, Fernández Sánchez C, et al. Sevoflurano tópico: una nueva opción terapéutica paliativa en las úlceras cutáneas. Med Paliat 2017:24:104-8.

12 Briggs M, Nelson EA, Martyn-St James M. Topical agents or dressings for pain in venous leg ulcers. Cochrane Database Syst Rev 2012;11:CD001177.

13 Jimenez ER, Whitney-Caglia L. Treatment of chronic lower extremity wound pain with nitroglycerin ointment. J Wound Ostomy Continence Nurs 2012;39:649-52.

14 Mayer A, Slezak V, Takac P, et al. Treatment of non-healing leg ulcers with honeydew honey. J Tissue Viability 2014;23:94-7.

15 Smith H, Brooks JR. Capsaicin-based therapies for pain control. Prog Drug Res 2014;68:129-46. 
16 Fassoulaki A, Skouteri I, Siafaka I, et al. Local application of volatile anesthetics attenuates the response to a mechanical stimulus in humans. Can J Anaesth 2005;52:951-7.

17 Cantrell FL. A fatal case of sevoflurane abuse. Clin Toxicol 2008:46:918-9.

18 Ilardi CF, Faro JC. Localization of parathyroid hormone-like substance in squamous cell carcinomas. An immunoperoxidase study with ultrastructural correlation. Arch Pathol Lab Med 1985;109:752-5.

19 Jiang J, Jiang $\mathrm{H}$. Effect of the inhaled anesthetics isoflurane, sevoflurane and desflurane on the neuropathogenesis of Alzheimer's disease (review). Mol Med Rep 2015;12:3-12.

20 Rueda-Martínez JL, Gerónimo-Pardo M, Martínez-Monsalve A, et al. Topical sevoflurane and healing of a post-operative surgical site superinfected by multi- drug-resistant pseudomonas aeruginosa and susceptible staphylococcus aureus in an immunocompromised patient. Surg Infect 2014;15:843-6.

21 Giorgi A, Parodi F, Piacenza G, et al. Antibacterial and antifungal activity of isoflurane and common anesthetic gases. Minerva Med 1986;77:2007-10.

22 Johnson BH, Eger El. Bactericidal effects of anesthetics. Anesth Analg 1979;58:136-8.

23 Ferrara P, Domingo-Chiva E, Selva-Sevilla C, et al. Irrigation with liquid sevoflurane and healing of a postoperative, recurrent epidural infection: a potential cost-saving alternative. World Neurosurg 2016;90:702.e1-5.

24 Bhattacharya S, Mishra RK. Pressure ulcers: current understanding and newer modalities of treatment. Indian J Plast Surg 2015;48:4-16. 